\title{
PEMANFAATAN INTERNET PADA PERPUSTAKAAN DAERAH KABUPATEN
}

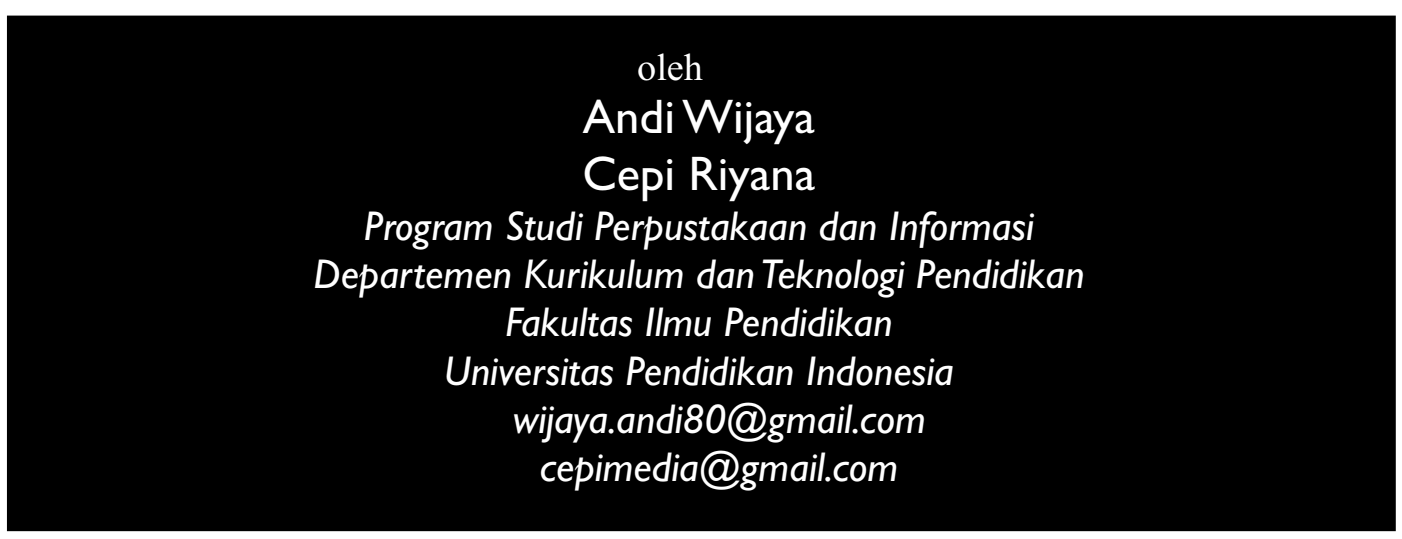

\begin{abstract}
ABSTRAK
Penelitian ini bertujuan untuk mengetahui kemajuan teknologi internet yang telah merambah ke segala segi kehidupan dari bidang ekonomi, bisnis, hiburan, budaya dan pendidikan, sampai dengan layanan perpustakaan. Khusus pemanfaatan internet di Perpustakaan Daerah Kabupaten Karawang. Penelitian ini menggunakan metode deskriptif dengan pendekatan kuantitatif. Populasi dalam penelitian ini adalah seluruh pemustaka yang menggunakan media internet pada Perpustakaan Daerah Kabupaten Karawang yang berjumlah 40 orang. Teknik sampling digunakan untuk menjaring data dari responden. Teknik pengumpulan data dilakukan dengan cara langsung dimana peneliti melakukan pengamatan secara langsung ke lokasi yang menjadi situs penelitian. Teknik langsung ini didukung oleh penyebaran angket kepada sejumlah responden penelitian yang juga menggunakan teknik wawancara dan observasi. Dalam menganalisis data digunakan tabel untuk mencari nilai rerata dari mean untuk setiap jenis data tersebut untuk memperoleh simpulan. Hasil penelitian menujukkan bahwa: pertama, pemustaka yang memanfaatkan internet pada Perpustakaan Daerah Kabupaten Karawang sering menggunakan cara searching dalam mencari informasi yang dibutuhkan. kedua, pemustaka yang memanfaatkan internet pada Perpustakaan Daerah Kabupaten Karawang dominan memanfaatkan fasilitas web. ketiga, pemustaka yang memanfaatkan internet jarang melakukan download informasi yang berada di internet pada Perpustakaan Daerah Kabupaten Karawang. Hasil penelitian menujukkan perlunya upaya berkelanjutan dari Perpustakaan Daerah Kabupaten Karawang untuk memperbaiki tingkat kekerapan kunjungan dan pemanfaatan internet secara maksimal.
\end{abstract}

Kata kunci : internet, sumber-sumber informasi, pemanfaatan, pemustaka. 


\begin{abstract}
This study aims to determine the progress of Internet technology has penetrated into every aspect of life from economics, business, entertainment, culture and education, up to the library service. Special use of the Internet in the Library District Khanewal. This study used a descriptive method with a quantitative approach . The population in this study were all pemustaka who use the internet at Falkirk District Library, amounting to 40 people . Sampling techniques used to collect data from respondents . Data was collected by means of direct observation in which the researcher directly to the location of the site of research. The technique is supported directly by distributing questionnaires to a number of survey respondents who also use interview techniques and observation. In analyzing the data tables used to find the average value of the mean for each type of data to derive conclusions. The results showed that : first, pemustaka who use the Internet at the Library District Khanewal often use the searching in the search for the required information. The second, which utilizes the internet to pemustaka Regional Library District Falkirk dominant utilizing the web facility. The third, which utilizes the internet rarely pemustaka to download information on the internet is in Karawang District Library . The results showed the need for the continued efforts of the Regional Library District Falkirk to improve the frequency of visits and use of the Internet to the fullest.
\end{abstract}

Keywords : internet, sources - resources, utilization, pemustaka 


\section{PENDAHULUAN}

Seiring dengan perkembangan pada era globalisasi, kini informasi bisa semakin mudah untuk diakses. Salah satu cara aksesnya adalah dengan menggunakan media internet. Perkembangan perpustakaan digital tidak lepas dari perkembangan teknologi informasi yang diperlukan oleh perpustakaan. Kini perpustakaan dibangun dengan teknologi web (jaringan internet), yang memungkinkan pengaksesan koleksi oleh pemustaka dan dapat berkomunikasi dengan pustakawan langsung kapan dan dimanapun pemustaka berbagai kalangan berada. Koneksi jaringan internet yang dipergunakan di perpustakaan adalah jaringan internet jenis Local Area Network (LAN). Jaringan LAN merupakan jaringan internet yang cakupannya meliputi wilayah kecil, misalnya satu ruangan atau satu gedung. Penggunaan jaringan ini di perpustakaan dikembangkan untuk melayani komunitas tertentu dan kelompok - kelompok melalui user (pemustaka) yang ada.

Sistem pencarian informasi terkini telah mengalami peningkatan, yang ditandai dengan adanya sistem pencarian informasi dengan cara online berjejaring. Internet adalah alat komunikasi bagi setiap orang untuk pencarian informasi dengan cara yang cepat, tepat dan akurat. Internet pada masa kini telah digunakan oleh masyarakat dari golongan manapun.

Pemanfaatan ICT (Information and Communication Technology - TIK, Teknologi Informasi dan Komunikasi) semakin beragam dan sudah mulai diaplikasikan dalam kehidupan seharihari. Oleh karena itu, pemerintah selaku penyelenggara tatanan hidup bernegara harus memberikan pengarahan, pelatihan, dan memfasilitasi layanan internet kepada masyarakat (Raharjo, 1995:3)

Jaringan informasi memberikan kesempatan luas bagi masyarakat untuk mengakses situs - situs berbagai lembaga yang menyediakan informasi. Salah satu lembaga informasi tersebut adalah perpustakaan. Sebagai bagian dari masyarakat dunia, perpustakaan ikut serta membangun masyarakat informasi berbasis TIK sebagaimana dituangkan dalam deklarasi World Summit of Information Society - WSIS, 12 Desember 2003. Sedangkan dalam UU tentang Perpustakaan No 43 Tahun 2007 dinyatakan bahwa perpustakaan harus menyediakan bahan pustaka tercetak dan terekam dalam berbagai media. Dalam hubungan ini, perpustakaan selain menyediakan berbagai sumber informasi, wajib menyediakan sarana navigasi untuk temu kembali informasi termasuk menyelenggarakan program pendidikan dan pelatihan melek teknologi, melek media dan melek informasi. Hal ini merupakan keahlian kritis bagi individu jika mereka ingin produktif dan efektif dalam kehidupan pribadi dan profesional mereka (McClure, 1994:15-25). Perpustakaan sendiri saat ini menyediakan koleksi digital baik asli (born digital) maupun hasil transformasi, dan perpustakaan dapat memanfaatkan dukungan infrastruktur dan menyediakan layanan internet.

Internet sendiri masuk ke Indonesia pada tahun 1983 ke Universitas Indonesia (UI) berupa UINet oleh Dr. Joseph Luhukay (Darma Oetama, 2007:2). Internet mempunyai banyak manfaat yang antara lain adalah sebagai alat komunikasi dan bersosialisasi. Melalui dunia maya, internet menawarkan fasilitas yang memudahkan cara berkomunikasi searah yaitu e-mail dan dua arah dengan chatting. Dengan fasilitas tersebut pengguna internet (pemustaka) dapat menjalin komunikasi secara cepat dan dengan biaya yang relatif murah. Dengan menggunakan surat kabar elektronik atau e-mail sebuah dokumen dapat dikirimkan secara cepat ke seluruh penjuru dunia dalam hitungan 
menit tergantung kecepatan koneksi, begitu juga fasilitas chatting yang memungkinkan dua pihak dapat saling mengirim teks, video, maupun kiriman data secara online dua arah secara langsung.

Manfaat internet bagi dunia pendidikan adalah bahwa internet dapat menghilangkan atau mengurangi hambatan ke sumber informasi (Andarwati, 2005:1-2). Pada mulanya akses ke sumber informasi harus melalui media cetak seperti buku dan majalah, namun sesuai dengan arus perkembangan dunia teknologi informasi yang begitu cepat maka sebuah lembaga informasi seperti perpustakaan harus dapat memenuhi sarana dan fasilitas untuk menyediakan sumber - sumber informasi. Selain itu, bagi kalangan akademika, materi yang berkaitan dengan proses kegiatan pembelajaran baik di lingkungan perpustakaan maupun lingkungan masyarakat harus relevan dengan kebutuhan.

Menurut Paijo (2006: 21-22) penggunaan internet di suatu perpustakaan dapat dibedakan kedalam dua hal, yaitu: Pertama, penyediaan akses berupa penyediaan sarana dan prasarana dimana pengguna perpustakaan dapat menggunakan internet. Dalam hal ini, perpustakaan menyediakan sejumlah akses yang bertujuan untuk memungkinkan pemustaka dapat memperoleh informasi yang bersumber dari website. Kedua, Internet sebagai publikasi yaitu kegiatan untuk mempublikasikan berbagai informasi tentang dan oleh perpustakaan. Dalam hal ini perpustakaan memiliki dan memelihara sendiri website penerbitan untuk mendiseminasikan berbagai informasi tentang perpustakaan dan kegiatan layanan dengan antara lain melibatkan berbagai macam kebutuhan pengguna perpustakaan dan fungsi internet. Seperti uraian di atas, maka Perpustakaan Daerah Kabupaten Karawang menyediakan fasilitas internet di ruangan baca, agar pemustaka lebih nyaman berada didalam ruangan perpustakaan yang sudah difasilitasi oleh perangkat elektronik.

Era globalisasi menuntut perpustakaan untuk melengkapi sarana dan fasilitas didalam penyediaan sumbersumber informasi dan sebagai daya tarik bagi pemanfaat koleksi perpustakaan untuk lebih jauh memahami dan mendapat informasi termasuk informasi tentang perkembangan ilmu pengtahuan dan teknologi. Cara pandang yang berkembang oleh para pemustaka telah menempatkan informasi sebagai salah satu komoditi utama dalam menunjang dinamika kehidupan oleh para pemustaka itu sendiri.

Kegiatan belajar oleh pemustaka berbagai kalangan di Kabupaten Karawang sudah menggunakan media teknologi yang berperan untuk mencari informasi yang diinginkan. Perpustakaan Daerah Kabupaten Karawang telah memfasilitasi layanannya yang berupa internet untuk sarana temu-kembali.

\section{PEMBAHASAN}

Kenyataan bahwa pada era informasi abad ini TIK atau ICT telah menjadi bagian yang tidak terpisahkan dari kehidupan global. Karena itu, setiap institusi termasuk perpustakaan pada lembaga pendidikan berlomba untuk mengintegrasikan "internet" guna membangun dan memberdayakan sivitas akademikanya agar dapat berdaya saing dalam era global. Dalam menyikapi perkembangan internet pada era informasi ini, perpustakaan berbasis internet sangat dibutuhkan di kalangan masyarakat. Keberadaan perpustakaan berbasis komputerisasi dapat meningkatkan kualitas dan kecepatan proses layanan pengguna perpustakaan sehingga dapat 
memperlancar proses dalam pencarian informasi di internet.

Perkembangan perpustakaan berbasis TIK bagi pengelola perpustakaan dapat membantu pustakawan melalui fungsi otomasi perpustakaan, sehingga proses pengolahan lebih efektif dan efisein. Fungsi otomasi perpustakaan adalah mengontrol sistem administrasi layanan sacara terkomputerisasi. Sedangkan bagi pengguna akan membantu mencari sumber informasi yang diinginkan dengan menggunakan online catalog yang dapat diakses melalui internet, sehingga akses ke reources dapat dilakukan kapanpun dan di manapun pengguna perpustakaan berada. Idealnya setiap perpustakaan memanfaatkan kecanggihan teknologi informasi untuk mendukung pengolahan koleksi perpustakaan.

Perkembangan dunia perpustakaan dilihat dari segi data dan dokumen yang disimpan di perpustakaan, dimulai dari perpustakaan tradisional yang hanya terdiri dari kumpulan koleksi buku tanpa katalog, kemudian muncul perpustakaan semi modern yang menggunakan katalog (index). Katalog mengalami metamorfosa menjadi katalog elektronik yang lebih mudah dan cepat dalam pencarian kembali koleksi yang disimpan di perpustakaan. Koleksi perpustakaan juga mulai dialihmediakan ke bentuk elektronik yang tidak memakan lebih banyak tempat dan mudah ditemukan kembali. Ini adalah perkembangan mutakhir dari perpustakaan, yaitu dengan munculnya perpustakaan digital (digital library) yang memiliki keunggulan dalam penelusuran informasi dan data yang lebih cepat dan mudah didapat karena berorientasi ke data digital dan media jaringan komputer (internet). Selain itu, dari segi manajemen (teknik pengolahan), dengan semakin mudahnya koleksi di perpustakaan diakses, saat ini muncul kebutuhan akan pengguna teknologi informasi untuk otomatisasi proses bisnis di perpustakaan. Sistem yang dikembangkan kemudian terkenal dengan sebutan sistem otomasi perpustakaan (library automation system) (Supriyanto, 2008:14).

Populasi adalah sekelompok orang, benda, hal yang menjadi sumber pengambilan sampel. (Alwi, 2007: 889). Sedangkan menurut pendapat Siswojo (2008: 56) definisi populasi adalah "sejumlah kasus yang memenuhi seperangkat kriteria yang ditentukan peneliti". Populasi dalam penelitian ini adalah anggota perpustakaan daerah yang berada di Kabupaten Karawang. Jumlah populasi penduduk Kabupaten Karawang keseluruhnya adalah 126.540 orang. Data ini di ambil dari kantor dinas kependudukan daerah sedangkan perpustakaan daerah sendiri mempunyai anggota aktif sebanyak 127 orang dari seluruh penduduk Kabupaten Karawang, dan data tersebut menjadi populasi penelitian ini.

Pada bagian ini disajikan data hasil penelitian kuantitatif yang diperoleh selama penelitian tentang pemanfaatan internet oleh pemustaka di Perpustakaan Daerah Kabupaten Karawang berdasarkan accidental sampling. Data diperoleh dari kuesioner yang diisi oleh 40 pengguna perpustakaan yang merupakan sampel penelitian.

Tabel 1.1

Kesimpulan Hasil Penelitian Penelusuran Menggunakan Searching

\begin{tabular}{|c|c|c|c|c|c|}
\hline Rategon & $\begin{array}{c}\text { Jumlah } \\
\text { Peasguna } \\
(\mathrm{A})\end{array}$ & $\begin{array}{c}\text { Pessen } \\
(\%)\end{array}$ & Sker & $\begin{array}{l}\text { Nilii } \\
\text { Anglet } \\
(\Sigma X)\end{array}$ & $\begin{array}{l}\text { Nean } \\
(\mathrm{Mx})\end{array}$ \\
\hline Sangut scisz & 7 & 17,5 & 4 & 28 & \multirow{4}{*}{$\begin{array}{l}105: 40 \\
=2,625\end{array}$} \\
\hline Sering & 13 & 32,5 & 3 & 39 & \\
\hline Jarag & 18 & 45,0 & 2 & 36 & \\
\hline Tidak penzak & 2 & 50 & 1 & 2 & \\
\hline Total & 40 & 100 & & 105 & \\
\hline
\end{tabular}


Menunjukkan sebanyak 7 pemustaka menyatakan sangat sering menggunakan Searching dan yang menyatakan sering sebanyak 13 pemustaka, sedangkan yang menyatakan jarang sebanyak 18 pemustaka, dan sebanyak 2 pemustaka menyatakan tidak pernah. Dengan demikian dari hasil penghitungan rumus mean, diperoleh nilai rata-rata sebesar 2,625. Berdasarkan nilai rata-rata tersebut dapat disimpulkan bahwa pemustaka ketika mengakses internet sering menggunakan cara Searching.

Tabel 1.2

Kesimpulan Hasil Penelitian Penelusuran Menggunakan Browsing

\begin{tabular}{|c|c|c|c|c|c|}
\hline Kutegon' & $\begin{array}{c}\text { Jumlah } \\
\text { Pestgena } \\
\text { (N) }\end{array}$ & $\begin{array}{l}\text { Persen } \\
\text { (\%) }\end{array}$ & Sker & $\begin{array}{l}\text { Nilai Angket } \\
\text { (2X) }\end{array}$ & $\begin{array}{l}\text { Nea } \\
(\mathrm{M} x)\end{array}$ \\
\hline Sangat sering & 2 & 5,0 & 4 & 8 & \multirow{4}{*}{$\begin{array}{l}105: 40 \\
=2,5\end{array}$} \\
\hline Seaing & 19 & 47,5 & 3 & 57 & \\
\hline Jeang & 16 & 40,0 & 2 & 32 & \\
\hline Tidak pemah & 3 & 7,5 & 1 & 3 & \\
\hline Total & 40 & 100 & & 100 & \\
\hline
\end{tabular}

Data Browsing menunjukkan bahwa sebanyak 2 pemustaka menyatakan sangat sering menggunakan cara Browsing, sedangkan sebanyak 19 pemustaka menyatakan sering, 16 pemustaka menyatakan jarang, dan 3 pemustaka menyatakan tidak pernah menggunakan cara Browsing didalam menelusur informasi. Dengan demikian dari hasil penghitungan rumus mean dapat diperoleh nilai rata-rata sebesar 2,5. Berdasarkan nilai rata-rata tersebut dapat disimpulkan bahwa pengguna jarang menggunakan cara Browsing dalam mencari informasi di internet.
Tabel 1.3

Kesimpulan Hasil Penelitian Pemanfaatan Web

\begin{tabular}{|c|c|c|c|c|c|}
\hline Kategon & $\begin{array}{l}\text { hamlah } \\
\text { Peagguna } \\
\text { (N) }\end{array}$ & $\begin{array}{l}\text { Persem } \\
\text { (ci) }\end{array}$ & Stort & $\begin{array}{l}\text { Nälai Angket } \\
\text { (EX) }\end{array}$ & $\begin{array}{l}\text { Mean } \\
\text { M(x) }\end{array}$ \\
\hline Sangut seing & 6 & 15,0 & 4 & 24 & \multirow{4}{*}{$\begin{array}{l}101: \\
40= \\
2,52\end{array}$} \\
\hline Seing & 13 & 32,5 & 3 & 39 & \\
\hline Jang & 17 & 42,5 & 2 & 34 & \\
\hline Tiduk pesal & 4 & 10,0 & 1 & 4 & \\
\hline Total & 40 & 100 & & 101 & \\
\hline
\end{tabular}

Data pada Tabel 4.3. menunjukkan bahwa sebanyak 6 pemustaka menyatakan sangat sering memanfaatkan $W e b$, sedangkan 13 pemustaka menyatakan sering, 17 pengguna menyatakan jarang, dan sebanyak 4 pemustaka menyatakan tidak pernah. Dengan demikian, dari hasil penghitungan rumus mean, diperoleh nilai rata-rata sebesar 2,52. Berdasarkan nilai rata-rata tersebut dapat disimpulkan bahwa pengguna sering menggunakan fasilitas web.

Tabel 1.3

Kesimpulan Hasil Penelitian Perolehan Informasi melalui Downloading

\begin{tabular}{|c|c|c|c|c|c|}
\hline Kategedi & $\begin{array}{l}\text { Jumlah } \\
\text { Peagguas } \\
\text { (N) }\end{array}$ & $\begin{array}{l}\text { Parm } \\
\text { (6i) }\end{array}$ & Skot & $\begin{array}{l}\text { Nalai Angke } \\
(2 \mathrm{X})\end{array}$ & $\begin{array}{l}\text { Mean } \\
(M x)\end{array}$ \\
\hline Sastat seriag & 3 & 7,5 & 4 & 12 & \multirow{4}{*}{$\begin{array}{c}84: 40= \\
2,1\end{array}$} \\
\hline Sering & 7 & 17,5 & 3 & 21 & \\
\hline Janang & 21 & 52,5 & 2 & 42 & \\
\hline Tidak penih & 9 & 22,5 & 1 & 9 & \\
\hline Total & 40 & 100 & & 84 & \\
\hline
\end{tabular}

Menunjukkan bahwa penggunaan internet untuk download adalah sebanyak 3 pemustaka menyatakan sangat sering, 7 pemustaka menyatakan sering, sebanyak 21 pemustaka menyatakan jarang, dan sebanyak 9 pemustaka menyatakan tidak pernah. Sehingga, dari hasil penghitungan rumus mean, dapat diperoreh nilai ratarata sebesar 2,1. Berdasarkan nilai ratarata tersebut dapat disimpulkan bahwa 
pemustaka jarang download ketika mengakses internet.

\section{SIMPULAN}

Setelah melakukan penelitian tentang "Pemanfaatan Internet pada Perpustakaan Daerah Kabupaten Karawang" maka dapat ditarik simpulan sebagai berikut:

1. Fasilitas internet yang dimanfaatkan pemustaka adalah dengan cara penelusuran informasi yaitu searching dan browsing. Dari kedua cara tersebut, yang sering digunakan oleh pemustaka dalam penelusuran informasi melalui internet di Perpustakaan Daerah Kabupaten Karawang adalah searching, yang ditunjukkan dengan nilai rata - rata 2,625, sedangkan browsing jarang digunakan, yang ditunjukkan dengan nilai rata - rata 2,5. Dengan demikian pemustaka lebih sering mengakses internet melalui cara searching dalam pencarian informasi maupun pencarian buku.

2. Penggunaan fasilitas internet yang telah dimanfaatkan oleh pemustaka Perpustakaan Daerah Kabupaten Karawang adalah web, yang ditunjukkan dengan nilai rata - rata 2,52. Dalam pemanfaatan internet oleh pemustaka di Perpustakaan Daerah Kabupaten Karawang atas kebutuhan informasi yang kemungkinan dapat di download adalah berupa berita, artikel, makalah, video klip/lagu, film, games dan file program. Dari berbagai jenis informasi tersebut, pemustaka jarang bahkan tidak pernah melakukan download dengan nilai rata - rata adalah 2,35. Pemustaka menggunakan web hanya untuk mengakses internet namun download jarang digunakan untuk kebutuhan yang lainnya.
3. Fasilitas internet pada Perpustakaan Daerah Kabupaten Karawang berfungsi sebagai sarana tukar menukar data, pencarian informasi, media komunikasi dan sarana hiburan pada masa ini. Internet adalah bagian hidup masyarakat sekitar untuk kebutuhan akan sumber pengetahuan dan wawasan yang penting sehingga internet dapat berperan sebagai kunci menuju peningkatan kualitas hidupnya.

4. Masih terdapat kendala dalam pemanfaatan internet yang dilakukan oleh pemustaka berupa jaringan internet terputus dan juga komputer yang sering mengalami error. Permasalahan ini mengurangi animo pemustaka untuk memanfaatkan fasilitas yang tersedia walaupun kecermatan menanggapi permasalahan yang terjadi didalam pemanfaatan internet di perpustakaan telah diperlihatkan oleh pihak perpustakaan.

Berdasarkan uraian tersebut maka dapat disimpulkan bahwa terdapat respon positif dari masyarakat Kabupaten Karawang sebagai pemustaka tentang "Pemanfaatan Internet pada Perpustakaan Daerah Kabupaten Karawang”. Semua ini akan membantu Perpustakaan Daerah Kabupaten Karawang untuk memperdayakan masyarakat sekitar dalam memanfaatkan internet di perpustakaan.

\section{DAFTAR PUSTAKA}

Alwi, S. (2007). Manajemen Sumber Daya Manusia, Strategi Keunggulan Kompetitif. Yogyakarta: Badan Penerbit Fakultas Ekonomi, Yogyakarta.

Andarwati, S. R \& Bambang S. S. (2005). Pemenuhan Kepuasan Pengguna Internet Oleh Pengguna Badan Litban Pertanian Di Bogor. Jurnal Perpustakaan Pertanian Vol. 14, 
Nomor 1.

McClure, C. (TT). Network Liberacy: a role for liberarie. Journal of Information Technology and Liberaries. June 1994.

Oetama, B. S. D. (2007). Perencanaan dan Pembangunan Sistem Informasi. Yogyakarta: Penerbit Andi.

Paijo. (2006). Teknologi Informasi dan Dampaknya Layanan Informasi Perpustakaan. Media Informasi Vol.XVNo.3.

Raharjo. (1995). Kerangka Dasar Sistem Informasi Manajemen: Bagian II Struktur dan Pengembangannya. Dalam Seri Manajemen No. 90-B. Jakarta: PT. Pustaka Binaman Pressindo.

Siswojo. (2008). Metode Penelitian Kepustakaan. Jakarta: Yayasan Obor Indonesia. 